\title{
ANNALS
}

OF THE

\section{AMERICAN ACADEMY}

OF

POLITICAL AND SOCIAL SCIENCE.

\section{GENIUS, FAME AND THE COMPARISON}

OF RACES.

Genius is that aptitude for greatness that is born in a man; fame is the recognition by men that greatness has been achieved. Between the two lie early nurture and training, schools, the influence of friends and books, opportunities, and, in short, the whole working of organized society upon the individual. One is biological, the other social; to produce geniuses is a function of race, to allot fame is a function of history.

The question I propose to consider is, What is the relation between these two things? Does genius always result in fame? If not, why not, what determines whether it shall or shall not do so? These, in a general way, are the inquiries which suggest themselves, and which one would like to answer. I shall be well content if, without attempting to answer them fully, I can bring forward facts or reasoning that shall throw any light upon the matter whatever. That the question is a great one I think no one will doubt for a moment. It is a part of that larger question which is, from one point of view at least, the very root [3I 7 ] 
problem of sociology, of history, perhaps of psychology, the question, that is, of the mutual relations between the individual and the social order, of how society makes the man and of how the man makes society. Although the "greatman-theory" of history, as taught by Carlyle and others, may not be entirely tenable, yet it is quite plain that recent studies in imitation, suggestion and the like have established more firmly than ever the fact of the momentous influence of remarkable men upon the progress of mankind.

One who wishes to work at this subject in as exact and verifiable a manner as its nature permits may well start, I think, from the writings of Francis Galton, and particularly from his great work on "Hereditary Genius." * In this book the author, though concerned primarily with heredity, has found it necessary to his purpose to formulate roughly and to defend a theory of the relation between genius and fame. This theory, which I shall presently elucidate by ample quotations, may be stated, so far as it is capable of brief statement, somewhat as follows: Fame-on the whole, and reserving the right to allow for special conditions-is a sufficient test of genius. Fame can seldom be attained without genius, and genius as a rule achieves fame. Social conditions, though sometimes important and occasionally decisive, may on the whole be regarded as disturbing forces, not at all comparable in influence to natural capacity. This is so far the case that the number of illustrious men a race is capable of producing from a given population may be used as a criterion of the ability of the race, and upon this basis comparisons may justifiably be made between races so remote from each other as the ancient Athenians and the modern English.

I am led by a study of the facts in the case to uphold the following somewhat different theory-for which, however, I claim no originality. Every able race probably turns out a

\footnotetext{
* Galton's later writings contain, I think, no essential modification of the riews set forth in "Hereditary Genius."
} 
number of greatly endowed men many times larger than the number that attains to fame. By greatly endowed I mean with natural abilities equal to those that have made men famous in other times and places. The question which, if any, of these geniuses are to achieve fame is determined by historical and social conditions, and these vary so much that the production of great men cannot justifiably be used as a criterion of the ability of races except under rare and peculiar circumstances hereafter to be specified.*

My view of the relation between genius and the social order may perhaps be made clear by the following comparison: Suppose a man, having plowed and cultivated his farm, should take in his hand a bag of mixed seeds-say wheat, rice, Indian corn, beans, and others-and should walk straight across his land, sowing as he went. All places on his path would be sown alike: the rocks, the sandy ground, the good upland soil, the rich mold in the hollows, the marshes, and whatever other sorts of soil there might be. All would be sown alike, but there would be a great variety in the result when harvest time came around. In some places nothing would come up at all. In the sand perhaps only the beans would flourish, in the marshes only the rice, and so on; while some generous soils would allow a variety of plants to grow side by side in considerable vigor. Something like this, I think, is the case with a stock of men passing through history. A good stock probably produces remarkable children with comparative uniformity, but of these only a few become famous men, and these few, instead of being evenly distributed, appear in

*Views more or less like this have been advawced by various writers; but $\mathrm{I}$ do not know that any one has treated the matter at length or answered Galton's arguments so much in detail as I have attempted to do in this paper.

Among the most important writings touching upon the subject are the article by Professor William James, entitled "Great Men, Great Thoughts and the Environment," in the Allantic Monthly for 1880 , page $44 \mathrm{I}$, and the replies to it by John Fiske ( $188 \mathrm{I}$, page 75) and Grant Allen (188I, page 37I).

L,ombroso's "Man of Gezius" contains, of course, much interesting matter bearing on this question. See especially Part II. 
groups, now of one sort, now of another, now of several sorts.

Before giving Galton's views at length let me point out that the question whether the production of great men is a fair criterion of race, together with the comparisons based upon the supposition that it is, is a side-issue, possibly an after-thought, in "Hereditary Genius," and in no way involves the main thesis of that work, which is that genius may be transmitted by heredity. I imagine that no one who reads the book will question that this thesis is fully proved. It would be strange, however, if the subordinate propositions were as carefully thought out and thoroughly established as the main one.

There is a good deal of statistical reasoning in Galton's work that is not essential to the present discussion. It will be enough to call to mind the fact that he supposes mankind, or any particular race of men, to be classified according to natural gifts in sixteen classes or grades, as follows, beginning with the highest grade and ending with the lowest: $\mathrm{X}-\mathrm{G}-\mathrm{F}-\mathrm{E}-\mathrm{D}-\mathrm{C}-\mathrm{B}-\mathrm{A}-\mathrm{a}-\mathrm{b}-\mathrm{c}-\mathrm{d}-\mathrm{e}-\mathrm{f}-\mathrm{g}-\mathrm{x}$. Of these B, $A, a$ and $b$ are the mediocre classes, and of course the most numerous; $F$ and $G$ include only men of very great abilities; $\mathrm{X}$ embraces all higher grades; $\mathrm{F}, \mathrm{G}$ and $\mathrm{X}$ together including only about two hundred and fifty men in a million; $f$ and all below are idiots.

From Chapter IV, which takes up the question, "Is reputation a fair test of natural ability?" It will be necessary, and I am sure interesting, to give somewhat extended quotations. The author first defines the meaning of the question:

"Let it clearly be borne in mind, what $\mathrm{I}$ mean by reputation and ability. By reputation, I mean the opinion of contemporaries revised by posterity-the favorable result of a critical analysis of each man's character, by many biographers. I do not mean high social or official position, nor such as is implied by being the mere lion of a London season; but I speak of the reputation of a leader of opinion, of an originator, of a man to whom the world deliberately acknowledges itself largely indebted. 
"By natural ability, I mean those qualities of intellect and disposition, which urge and qualify a man to perform acts that lead to reputation. I do not mean capacity without zeal, nor zeal without capacity, nor even a combination of both of them, without an adequate power of doing a great deal of very laborious work. But I mean a nature which, when left to itself, will, urged by an inherent stimulus, climb the path that leads to eminence, and has strength to reach the summit - one which, if hindered or thwarted, will fret and strive until the hindrance is overcome, and it is again free to follow its labor-loving instinct. It is almost a contradiction in terms to doubt that such men will generally become eminent. On the other hand, there is plenty of evidence in this volume, to show that few have won high reputations, without possessing these peculiar gifts. It follows that the men who achieve eminence, and those who are naturally capable, are, to a large extent, identical.

"I believe, and shall do my best to show, that, if the 'eminent' men of any period had been changelings when babies, a very fair proportion of those who survived and retained their health up to fifty years of age, would, notwithstanding their altered circumstances, have equally risen to eminence."

To support this view he relies chiefly upon three arguments :

"I. That men who are gifted with high abilities-even men of class $\mathrm{E}$-easily rise through all the obstacles caused by inferiority of social rank.

"2. Countries where there are fewer hindrances than in England, to a poor man rising in life, produce a much larger proportion of persons of culture, but not of what I call eminent men.

" 3. Men who are largely aided by social advantages, are unable to achieve eminence, unless they are endowed with high natural gifts."

Concerning the first point he remarks:

" Now, if the hindrances to success were very great, we should expect all who surmounted them to be prodigies of genius. The hindrances would form a system of natural selection, by repressing all whose gifts were below a certain very high level. But what is the case? We find very many who have risen from the ranks, who are by no means prodigies of genius; many who have no claim to 'eminence' who have risen easily in spite of all obstacles. The hindrances undoubtedly form a system of natural selection that represses mediocre men, and even men of pretty fair powers--in short the classes below 
$\mathrm{D}$; but many of $\mathrm{D}$ succeed, a great many of $\mathrm{E}$, and $\mathrm{I}$ believe a very large majority of those above.

"If a man is gifted with vast intellectual ability, eagerness to work, and power of working, I cannot comprehend how such a man should be repressed. The world is always tormented with difficulties waiting to be solved-struggling with ideas and feelings, to which it can give no adequate expression. If, then, there exists a man capable of solving these difficulties, or of giving a voice to these pent-up feelings, he is sure to be welcomed with universal acclamation. We may almost say that he has only to put his pen to paper, and the thing is done. I am here speaking of the very first-class men-prodigies-one in a million, or one in ten millions, of whom numbers will be found described in this volume, as specimens of hereditary genius."

In speaking of "countries where there are fewer hindrances than in England" Galton has in mind the United States. He points out that:

"The Americans have an immense amount of the newspaperarticle-writer, or of the Member-of-Congress stamp of ability; but the number of their really eminent authors is more limited even than with us. I argue that, if the hindrances to the rise of genius were removed from English society as completely as they have been removed from that of America, we should not become materially richer in highly eminent men."

In this connection he urges with great vigor that while common men require sympathy and other favorable circumstances to induce them to put forth their energies, the generality of those who have gained great reputations are "haunted and driven by an incessant instinctive craving for intellectual work. If forcibly withdrawn from the path that leads toward eminence, they will find their way back to it, as surely as a lover to his mistress. They do not work for the sake of eminence, but to satisfy a natural craving for brain work, just as athletes cannot endure repose on account of their muscular irritability, which insists upon exercise. It is very unlikely that any conjunction of circumstances should supply a stimulus to brain work commensurate with what these men carry in their own constitutions. The action of external stimuli must be uncertain and intermittent, owing to their very nature; the disposition abides. It keeps a man ever employed-now wrestling with his difficulties, now brooding over his immature ideas-and renders him a quick and eager 
listener to innumerable, almost inaudible teachings, that others less keenly on the watch, are sure to miss."

The proposition that social advantages without high natural gifts will not enable a man to achieve real eminence Galton supports by an ingenious argument, which I omit in the belief that the fact will not be seriously questioned.

A youth of very great abilities, Galton asserts, is almost independent of ordinary school education. The best care that a master can take of him is to let him alone, just directing a little here and there, and checking desultory tendencies.

". . the most illustrious men have frequently broken loose from the life prescribed by their parents, and followed, careless of cost, the paramount dictation of their own natures; in short, they educate themselves. D'Alembert is a striking instance of this kind of self-reliance. He was a foundling (afterward shown to be wel!bred as respects ability), and put out to nurse as a pauper baby to the wife of a poor glazier. The child's indomitable tendency to the higher studies could not be repressed by his foster-mother's ridicule and dissuasion, nor by the taunts of his schoolfellows, nor by the discouragements of his schoolmaster, who was incapable of appreciating him, nor even by the reiterated deep disappointment of finding that his ideas, which he knew to be original, were not novel, but long previously discovered by others."

\section{Moreover,}

"A prodigal nature commonly so prolongs the period when a man's receptive faculties are at their keenest, that a faulty education in youth is readily repaired in after life."

This is illustrated by the case of Watt, whose general education was acquired after he was advanced in years, and also by that of Julius Cæsar Scaliger.

"The scholar who, in the eyes of his contemporaries and immediate successors, made one of the greatest reputations, as such, that any man has ever made, was Julius Cæsar Scaliger. His youth was, I believe, entirely unlettered. He was in the army until he was twenty-nine, and then he led a vagrant professional life, trying everything and sticking to nothing. At length he fixed himself upon Greek. 'His first publications were at the age of forty-seven, and between that time and the period of a somewhat early death, 
he earned his remarkable reputation, only exceeded by that of his son."

These observations are to be understood as applying only to literary men and artists, who, however, form the bulk of those that attain to eminence. In the case of statesmen, commanders and demagogues, Galton admits that great weight must be allowed to social advantages and the accident of being born at an opportune time. I need not dwell upon this, however, as I propose to deal chiefly with those careers which he himself looks upon as affording the strongest support to his argument. In conclusion,

"I see no reason to be dissatisfied with the conditions under which I am bound, of accepting high reputation as a very fair test of high ability. . . . I feel convinced that no man can achieve a very high reputation without being gifted with very high abilities; and I trust I have shown reason to believe, that few who possess these very high abilities can fail in achieving eminence."

From these quotations the reader can judge for himself whether it is not a fair description of Galton's theory to say that he holds social and historical conditions to be no more than disturbing forces in the career of genius. They may hasten or retard its success, but on the whole "few who possess very high abilities can fail in achieving eminence." That this is really his position must also be inferred from the fact that in another chapter, which I shall take up later, he estimates the comparative worth of different races on a basis of the number of great men they produce, without any attempt to compare their histories, or take account of their actual state of social development. Exceptions are here and there admitted, as, for instance, where he says that the Negroes in the United States have not had a fair chance to compete with the whites, but as to the general tenor of the book there can, I imagine, be no question.

Now let us first of all inquire what the facts and arguments quoted really show, supposing that we admit their general truth and reasonableness. They show that some men of genius can and do rise from a rather low rank of 
life-such as that in which d'Alembert passed his boyhoodand attain celebrity at an early age. This, I think, is nearly all that is shown: at any rate I wish to point out the following deficiencies in the reasoning:

I. It is not proved, or even claimed, except by inference, that there do not exist hindrances, greater than those surmounted by d'Alembert and others cited by Galton, which act as an effectual bar to genius. I shall give reasons for believing that such hindrances do exist, that they are effectual, and that they operate upon a large part of the population.

2. It is not shown, except by questionable a priori reasoning, that the ability to surmount ordinary social obstacles, proved to exist in certain cases, can be presumed to exist in men of genius as a class.

3. Finally, and most important omission of all, there is nothing to show that the ripening of genius into fame is not so far a matter of historical development-apart from the question of race-that race can at most be regarded as one of several equally important factors that must unite in the production of distinguished men. If this last be the case it follows that to estimate the worth of races merely by a count of famous men and withont a comparison of their history and social organization, is a quite unjustifiable proceeding.

In the discussion that follows I shall give the grounds for my opinion that these omitted propositions not only are not established but cannot be, and that in fact the reverse of each one of them is true.

It does not seem to me that Galton is altogether convincing in the examples he cites to show that genius is superior to social hindrances. What is said of d'Alembert is, of course, true, but it should perhaps be added that his father, although not disclosing himself, recognized the child's natural claims by settling upon him in infancy an annuity of 1200 francs; also that the son was sent to school at four 
years of age. A boy brought up by a kind foster-mother, in the principal centre of European culture, and with this income to give him a start, can scarcely be said to have labored under excessive social disadvantages. The case of Julius Cæsar Scaliger would indeed be remarkable if it could be shown that he was entirely illiterate in his youth, commenced the study of medicine at twenty-nine or later, and finally at middle age took up classical learning and became a famous scholar. If this were true it would be the only case I remember to have met with in which a man, grown up in illiteracy, afterward acquired fame as a scholar or a man of letters; and I doubt whether other cases can be produced. Galton's phrase "entirely unlettered" may mean no more than that he had a merely elementary education; but the facts, as gathered from the more accessible books of reference, seem scarcely to sustain the opinion that he was entirely unlettered in any sense. The "Encyclopedia Britannica" says-apparently quoting an account derived from Scaliger himself-

"At the age of twelve he was presented to his kinsman, the emperor Maximilian, and placed by him among his pages. He remained for seventeen years in the service of the emperor, following him in his expeditions through half of Europe, and distinguishing himself no less by personal bravery as a soldier than by military skill as a captain. But he was unmindful neither of letters, in which he had the most eminent scholars of the day as his instructors, nor of art, which he studied with considerable success under Albert Dürer."

It appears, however, that Scaliger's own account of his youth, and the only one which gives details, is regarded as quite untrustworthy. "Chambers' Encyclopedia,"' Michaud and others agree upon this point. The "American Encyclopedia" says,

"He claimed descent from the Scaligeri (or family Della Scala): sovereign princes of Verona from 1260 to 1367 , and asserted that he began his classical and medical studies when he was between thirty and forty years old. This story has been disproved by Scipio Maffei and Tiraboschi. The latter says he was the son of an illuminator of 
Venice, a native of Padua, named Benedetto Bordone, and that the son studied at Padua in his youth."

This false account of himself is ascribed to his vanity, which is known to have been extreme. On the whole I think I am justified in counting Scaliger's case out.

Is there, then, any form of social hindrance or disqualification that operates at all widely and effectually to prevent men of natural genius from achieving literary fame? I think there is at least one that has operated very widely and, so far as I can learn, quite effectually, namely, the circumstance of having been brought up without such an elementary education as consists in learning to read and write and having some access to good books.

In none of the cases cited by Galton of those who have attained to literary fame did the man in question fail to receive in his boyhood these simple tools by which all literary activity is carried on. Genius is wonderful, but not miraculous. A little suggestion, a little opportunity will go a great way with it-as Galton justly insists-but something of the sort there must be. A man can hardly fix his ambition upon a literary career when he is perfectly unaware, as millions are, that such a thing as a literary career exists. Between illiteracy and the ability to read a few good books there is all the difference between blindness and sight.

It is true that when reading and writing are generally diffused among the common people and recognized as necessary to any sort of advancement, a bright boy will manage to pick them up even when he has not been educated by his parents. But how recent the times and how few, even now, are the countries of which this can be said! Where whole classes of the people, or whole regions of the country know nothing of these difficult arts, how is a boy to get his start? How get that definite ambition that must go before any great achievement?

My opinion that an untaught childhood is an effectual bar to the development of literary genius does not, however, 
rest upon a priori arguments. Galton's list, as I have remarked, furnishes no example to the contrary. I have also, with the aid of Nichol's "Tables of European History, " prepared a list of about seventy of the most distinguished poets, philosophers and men of letters of Europe, consisting chiefly of those whose names are printed in large capitals by the authors of this work.* Having examined the biographies of these men I find none who did not receive elementary instruction in his boyhood. In the few cases where men of letters have sprung from a class generally illiterate it appears that some special pains has been taken with their education. Thus the father of Burns "was at great pains to give his children a good education," and Bunyan, whose father was a tinker, "a settled and reputable man," $\dagger$ says in his autobiography, "Notwithstanding the meanness and inconsiderableness of my parents it pleased God to put into their hearts to put me to school, to learn both to read and to write"

The next question is whether this hindrance of illiteracy, which appears to have been effectual, has been felt by a large proportion of the population. Exact information upon this point cannot be had except for recent times, but the following statements are moderate and I have taken some pains to satisfy myself of their truth. $\ddagger$

Up to within the present century the great mass of the population of Europe, even in Protestant countries, was entirely illiterate. By the great mass I mean all but a rather small per cent, differing in different countries and nowhere precisely ascertainable. $\$$

If we except France and Switzerland, the same is true of southern and eastern Europe at the present time. Spain, Russia and European Turkey are overwhelmingly illiterate.

*I give the list infra, page 15 .

† Venables' "Life of Bunyan," page $r_{3}$.

$\ddagger$ For information and references upon this point $I$ am indebted to the kindness of Prof. B. A. Hinsdale.

This was certainly the general fact. There may have been local exceptions. 
Italy is prevailingly so, though her condition in this respect is rapidly improving. The same may be said of Greece. In Austria-Hungary more than half of the army recruits are now returned as able to read and write; but we must remember that these are young men who have profited by recent reforms.

In England, where a powerful aristocracy and church establishment seem to have been, on the whole, hostile to the education of the common people, stich education has been more backward than in any other large Protestant country.

This latter statement may be verified by referring to a work upon "The Education of the Poor in England and Europe," published in 1846 , by Joseph Kay, B.A., of Trinity College, Cambridge. This book, which is largely statistical and descriptive, contains ample evidence that the common people of England were generally illiterate at this comparatively recent date, that the opportunities for their instruction, though greatly improved since 1830 , were miserably poor, and that the country was in this respect far behind the more enlightened nations of the continent. The author uses such expressions as these: "Our operatives and agricultural laborers are wholly uneducated." * "However miserable the instruction of the poor may be in the towns and great mining and manufacturing districts, that of the agricultural laborers is still worse provided for." $\dagger$ " Over great tracts of country there does not at present exist a single school." $\ddagger$ And concludes his last chapter thus:

"Yes, here, in such a country as this, where the aristocracy is richer and more powerful than that of any other country in the world, the poor are more depressed, more pauperized, more numerous in comparison to the other classes, more irreligious, and very much worse educated than the poor of any other European nation, solely excepting uncivilized Russia and Turkey, enslaved Italy, misgoverned Portugal, and revolutionized Spain."'

* Page xii.

+ Page xiv.

f Page 338.

l Page 364 
There are other hindrances arising from social and economic conditions that operate effectually to prevent the development of natural ability. One of these, as I suppose everyone will admit, is underfeeding in childhood, or the subjection of children to premature and stunting labor. No breeder of horses would expect a colt, however excellent his parentage, to develop speed after having been put to the plow when two years old. Yet it is undeniable that something closely analogous happens to a considerable part of the children in countries so advanced as England and the United States. Mr. Galton has himself devised and brought into use methods of measuring large numbers of men which have recently been employed to determine the physical effects of nurture and environment. The most striking of these researches is perhaps the investigation by Spielmann and Jacobs of the comparative measurements of Jews in the Fast and West Ends of London. * The West End Jews, who are a well-to-do class, did not differ much from Englishmen of the same class. Those from the East End, employed for the most part in sweat-shops upon the manufacture of cheap clothing, averaged more than three inches less in stature, and were inferior also in size of skull and in every particular covered by the measurements. The intellectual deterioration that goes with this cannot well be measured, but that it must exist will hardly be doubted.

In another paper, $\uparrow$ dealing with the ability of the Jews as compared with other races, Mr. Jacobs asserts that out of one and a half million of Jews living to fifty "only a little more than half a million can be said to have lived; the rest have but existed, and have been out of the running in the race for fame."

The biographies of men of letters seem to me to afford very small support to the theory that literary genius is

\footnotetext{
"See their paper on "The Comparative Anthropometry of English Jews" in the Journal of the Anthropological Institute, 1890, p. 76 .

+ Ibial, 1885, p. 35r. "The Comparative Distribution of Jewish Ability."
} 
independent of social hindrances. In going over the list already mentioned of seventy of the most distinguished European poets, philosophers and historians, I find that about two-thirds of them belonged by birth to the upper and upper middle classes, using the latter term rather broadly to include clergymen, advocates, well-to-do merchants and the like. Of the remainder nearly all came of the lower middle class, shopkeepers, prosperous handicraftsmen, etc., while the very few men who, like Burns, sprung from the peasantry, prove to have received an education uncommon in their class. It would seem, then, that if we divide mankind into these three classes, the number of famous men produced by each class is in something like inverse proportion to the total number in the class.*

The only escape from these facts, for one who still believes that genius is superior to circumstance, is to assert that the lower classes are naturally as well as socially inferior, and this to such a degree that few or no men of genius are born in them. In our democratic days this will appear to most persons a monstrous supposition, and yet it may be supported by a plausible argument which ought, in fairness, to be stated.

The struggle for the best places in life operates, it may be said, as a sort of natural selection, by the working of which the ablest strains of men are continually finding their

- Seventy-one famods European Men of Letters, Rodghly Classified ACcording to Birth and Hereditary Circumstances.

Belonging to the Upper and Upper Middle Classes.-Dante, Petrarch, Boceaccio, Chaucer, Ariosto, Montaigne, Spenser, Tasso, Cervantes, Shakespeare, Bacon, Jonson,(?) Descartes, Milton, Corneille, Hobbes, Pascal, Dryden, Leibnitz, Locke, Addison, Montesquieu, Voltaire, Fielding, Hume, Johnson, Lessing, Gibbon, Corvper, Burke, Goethe, Coleridge, Scott, Landor, Byron, Shelley, Niebuhr, Macaulay, Comte, Hugo, Thackeray, Disraeli, Tennyson, Browning, Ruskin-45.

Belonging to the Lower Middle Class,-Luther, Rabelais, Camoens, Erasmus, J. C. Scaliger, Moliere, Spinoza, Racine, Defoe, Swift, Steele, Pope, A. Smith, Rousseau, Kant, Schiller, Wordsworth, Hegel, Keats, Béranger, Heine, Balzac, Carlyle, Dickens-24.

Belonging to the Lower Class.-Bunyan, Burns-2.

of course, in the case of many of these men the classification is arbitrary, and probably no two persons would agree precisely upon such a matter. I do not think, though, that any reasonable changes would aiter the general result. 
way to the top. Even in the most conservative societies there is always more or less penetration of social walls by men and families of uncommon energy. The natural effect of such a process is that hereditary ability becomes concentrated in the upper strata, and little or none is to be found anywhere else. To this might be added the argument already quoted from Galton, that since America, where education is diffused and opportunity open, does not produce more great writers than England, where social distinctions are comparatively fixed, we must conclude that democracy has no tendency to bring to light suppressed genius.

This view has some show of reason, and in fact it may be admitted that, for the cause mentioned, there is probably more unusual ability among the children of the well-to-do classes, in proportion to their number, than there is among those who have not made so good a place for themselves. But there is no proof that this superiority is very great, and when we see that a few men from the peasantry and the proletariat, having had instruction and opportunities unusual with their class, achieve literary fame, it seems reasonable to infer that if instruction and opportunity had been general the number of such men would have been correspondingly increased.

The argument derived from the United States is pertinent only if we assume that the failure of this country to produce a large number of famous writers cannot be explained by some historical cause, such as the inevitable preoccupation of the people with the material development of the country and its political organization. That it can be so explained is the general and defensible opinion with us, and I shall later offer some observations tending to confirm this view.

Moreover, if we take history as a whole, the proposition that democracy favors the development of genius will appear plausible, to say the least.* Athens and Florence, rich in

*This topic is ably discussed in Bryce's "American Commonwealth," Caps. 107 and 108. 
famous men above all other places, were ciemocracies when at the height of their glory, and ceased to be glorious soon after they ceased to be democratic. The great writers of the Augustan age were the product of the later days of the Roman Republic, and the time of Elizabeth was one of freedom and open opportunity compared with the times that preceded and followed it. The history of the Netherlands would also offer striking confirmation of the theory suggested.

Freedom is certainly not the only cause of the appearance of great men, but it appears to be one of the causes, a favoring circumstance which has commonly united with other and more obscure conditions in the production, of memorable groups of famous persons. It seems to me that if any conclusion upon this point is to be drawn from history it is the one opposite to that which Galton draws from the case of the United States. And if this fails, what other standing ground is there for the theory that genius is not suppressed by illiteracy and class distinctions?

The question how far genius can be helped or hindered by such differences of wealth and circumstance as are found within the educated classes of peoples as advanced as the English or the American, cannot be precisely determined because we have no way of knowing what a man might have done under different conditions. We cannot know what is in him until it comes out: if genius does not become fame we cannot be sure it was genius. There is no single, definite obstacle which, like illiteracy, is almost invariably efficacious; but what may help one may hinder another. In such a question more weight must be given to probability and the opinion of judicious observers than to anything else. Galton is very clear in his belief that these things do not materially affect the final result, that if a man of genius does not reach fame by one road he will by another. It is possible, however, that he does not do full justice to the considerations opposed to this view.

That poverty, low rank, bad luck and the like are no [333] 
effectual bar to energetic men has been a thousand times proved. Indeed there is quite a general impression, borne out by ordinary observation, that men as a rule require a certain amount of opposition and hardship to bring out what there is in them. "'To be thrown upon one's own resources," says Franklin, "is to be cast in the very lap of fortune; for our faculties then undergo a development and display an en. ergy, of which they were previously unsusceptible." Human nature, as a rule, is sluggish, needing some sort of external occasion and incitement, and men of genius are not always exceptions to this rule. Galton says of Talleyrand,

"Tallyrand would have passed his life in the same way as other grand seigneurs, if he had not been ejected from his birthright by a family council on account of his deformity, and thrown into the vortex of the French Revolution. The furious excitement of the game overcame his inveterate indolence, and he developed into the foremost man of the period, after Napoleon and Mirabeau."*

I know of no reason to suppose that inveterate indolence is confined to diplomats or statesmen. Thackeray, among modern men of letters, is accused of it, perhaps unjustly, as some who knew him assert. At any rate Trollope says of him, $\uparrow$

"It was his nature to be idle-to put off bis work-and then to be angry with himself for putting it off. Ginger was hot in the mouth with him, and all the allurements of the world were strong upon him. To find on Monday morning an excuse why he should not on Monday do Monday's work was, at the time, an inexpressible relief to him, but had become a deep regret-almost a remorse-before the Monday was over."

It is possible that had Thackeray been rich he would never have settled down energetically to literature, but would have continued through life the desultory activities of his youth and early manhood.

I think it is true, however, that most artists and men of letters have the hair-trigger temperament described by Galton and feel almost continually a powerful impulse toward

* Op. cit., p. 46.

$\dagger$ “Irife of Thackeray," p. I5. 
production. But although this impulse is powerful it may be vague, a mere unrest and discontent; indeed it must be so until it finds its proper use through observation, opportunity and training. If this self-knowledge and wholesome activity are not gained, men of genius are peculiarly apt to sink in dissipation energies that do not readily find a natural outlet. The muscular sensibility of the born athlete, to which Galton likens the promptings of genius, seldom causes him to keep in training except when there is a fight or a race in prospect. At other times he is not unlikely to appease his uncomfortable sensations with drink. In the same way, I believe, genius, especially of the imaginative sort, is liable to run wild unless it finds betimes a harness in which it can work. This is the common impression, and the irregular lives of many gifted men bear it out.

There is a class of men of genius in whom extreme sensitiveness, combined with lack of physical vigor, makes it essential that they should be secluded from the stress and annoyance of bread-winning activities. The case of Darwin, as Professor Ritchie has suggested,* may be cited as one in which, so far as we can see, inherited wealth could not well have been dispensed with.

"Half an hour more or less conversation would make to him the difference of a sleepless night, and of the loss perhaps of half the next day's work." $\dagger$

After speaking of the routine of his life, in which everything that wealth, retirement and the affection of his family could do, combined to secure regularity, amusement and freedom from disturbance, his son goes on to say, $\ddagger$

"It is almost impossible, except for those who watched his daily life, to realize how essential to his well-being was the regular routine that I have sketched; and with what pain and difficulty anything beyond it was attempted. Any public appearance, even of the most modest kind, was an effort to him. In $187 \mathrm{I}$, he went to the little

- "Darwinism and Politics," p. 5I.

$\dagger$ "Life and Letters of Charles Darwin," Vol. i, p. ror.

\pm roid., p. ro5. 
village church for the wedding of his elder daughter, but he could hardly bear the fatigue of being present through the short service."

A notable instance of good fortune in Darwin's life was his appointment to be naturalist of the Beagle, leading him to settle finally upon a scientific career and enabling him to make those observations in which most of his later work was rooted. Just how far his development depended upon this opportunity it would be useless to discuss. It is very possible that he might have collected his material in some other way. In connection with this appointment there is an instance, related in his autobiography, of how great matters may hinge upon small ones.

"Afterward, on becoming very intimate with Fitz-Roy (the captain of the vessel) I heard that I had run a very narrow risk of being rejected, on account of the shape of my nose! He was an ardent disciple of Lavater, and was convinced that he could judge of a man's character by tise outline of his features; and he doubted whether any one with my nose could possess sufficient energy and determination for the voyage."*

As this question of the power of education and circumstance to help or hinder genius is largely a matter of opinion, I may be excused for quoting Goethe, whose wide acquaintance with every sort of natural ability and close study of the way in which it develops, make him perhaps the highest authority that can be found. Speaking of the fact that distinguished men, especially poets, are often sickly, he said to Eckermann, $\dagger$

"The extraordinary performance of these men presupposes a very delicate organization, which makes them susceptible to unusual emotions, and capable of hearing celestial voices. Such an organization, in conflict with the world and the elements, is easily disturbed and injured: and he who does not, like Voltaire, combine with great sensibility an equally uncommon toughness, is easily exposed to perpetual indisposition."

And again, in "Wilhelm Meister," $\ddagger$

“' But will not a happy natural turn,' said Wilhelm, 'as the first

* Ibid., p. 50.

†Conversation with Eckermann, Dec. 20, 1829.

$\lceil$ Book 2, cap. ix. 
and last requisite, of itself conduct the player, like every other artist, nay perhaps every other man, to the lofty mark he aims at?'

" "The first and last, the beginning and the end, it may well be; but in the middle many things will still be wanting to an artist, if instruction, and early instruction too, have not previously made that of him which he was meant to be: and perhaps for the man of genius it is worse in this respect than for the man possessed of only common capabilities; the one may much more easily be misinstructed, and be driven far more violently into false courses than the other.'

"' 'But,' said Wilhelm, 'will not genius save itself, not heal the wounds which itself has inflicted?' 'Only to a very small extent and with great difficulty,' said the other, 'or perhaps not at all.' ",

In estimating the importance of circumstance it should never be forgotten that "a favorable environment" is nothing fixed and definite, like social standing or wealth, but is different for every individual. That measure of struggle and disappointment which is only a wholesome and needed stimulus to one man, may drive another into dissipation, or wear out his body and mind with fruitless annoyance and anxiety. In the same way the wealth that may secure just the needed seclusion and materials for one, may keep another in lifelong indolence.

So much for those differences in education, nurture and opportunity that are found among the people of the same time and nation. Now how is it as between different countries and different times? Can it be shown that there are forces apart from race that cause genius to flourish here and droop there, which at one period foster the germs of greatness in a people until they yield a rich fruitage of accomplishment and fame, and at another wither and chill them into barrenness? Are such things as historical tendency and the spirit of the age sufficiently real and powerful to controi the production of famous men?

If the affirmative of these questions can be established, it is clear that the whole plan of estimating the worth of races by their great men and with only incidental reference to their history falls to the ground. Such comparisons can 
be defended only upon the theory that race is the paramount factor.

I hope to show that history is quite as important as race in this matter; that while it is a function of race to turn out geniuses, historical forces determine how many of them shall be famous, and of what sort these shall be, that the appearance of great men in the past has been of a sort impossible to reconcile with the theory that such appearance is controlled by race alone.

Let me begin by giving the main argument and conclusions of Galton's chapter on "The Comparative Worth of Different Races."

In discussing this the first question considered is, What are the qualities which are needed in civilized society, and which may, therefore, be used as a test of the worth of races?

"They are, speaking generally, such as wiii enable a race to supply a large contingent to the various groups of eminent men, of whom I have treated in my several chapters. Without going so far as to say that this very convenient test is perfectly fair, we are at all events justified in making considerable use of it, as I will do, in the estimates I am about to give."

The comparison, then, is to be based upon the number and grade of the eminent men that a race produces, the supposition being that the distribution of ability is similar in all races, so that if the ablest men in a given race are superior in a certain degree to those of another race, the men of medium and low ability will be superior in like degree. It is like the inference of a zoologist, who, having only a single bone of an animal of known species, will compute approximately all the other dimensions.

"I know this cannot be strictly true, for it would be in defiance of analogy if the variability of all races were precisely the same; but, on the other hand, there is good reason to expect that the error introduced by the assumption cannot sensibly affect the off-hand results for which alone I propose to employ it; moreover, the rough data I shall adduce, will go far to show the justice of this expectation." 
Upon this basis Galton proceeds to compare the Negro race with the Anglo-Saxon, the Lowland Scotch and the English North-Country men with the ordinary English, and the English with the ancient Athenians.

The Negro race he finds to be about two grades below the Anglo-Saxon. This conclusion is based upon the fact that its greatest men, such as Toussaint l'Ouverture, appear to be at least that much inferior to the greatest men of the rival race, also upon the opinions of travelers who have had to do with African chiefs, and upon the large proportion of half-witted persons found among the blacks.

The Lowland Scotch and the English North-Country men are held to be "decidedly a fraction of a grade superior to the ordinary English," both because they produce more eminent men in proportion to their number, and because the well-being of the masses of the population is greater.

We now come to the Athenians.

"Of the various Greek sub-races, that of Attica was the ablest, and she was no doubt largely indebted to the following cause for her superiority. Athens opened her arms to immigrants, but not indiscriminately, for her social life was such that none but very able men could take any pleasure in it; on the other hand, she offered attractions such as men of the highest ability and culture could find in no other city. Thus, by a system of partly unconscious selection, she built up a magnificent breed of buman animals, which, in the space of one century-viz., between 530 and 430 B. C.-produced the following illustrious persons, fourteen in number:

"Statesmen and Commanders. - Themistocles (mother an alien), Miltiades, Aristides, Cimon (son of Miltiades), Pericles (son of Xanthippus, the victor at Mycale). Literary and Scientific Men.Thucydides, Socrates, Xenophon, Plato. Poets. - Aeschylus, Sophocles, Euripides, Aristophanes. Sculptor. - Phidias.

The population of Attica at the time she produced these men consisted, it seems, of about 90,000 native free-born persons, 40,000 resident aliens, and a laboring and artisan population of 400,000 slaves. Of these Galton holds that the first-mentioned alone are to be considered, the aliens 
and slaves being excluded, doubtless because they did not belong to the Athenian race.

"Now let us attempt to compare the Athenian standard of ability with that of our own race and time. We have no men to put by the side of Socrates and Phidias, because the millions of all Europe, breeding as they have done for the subsequent 2000 years, have never produced their equals. They are therefore two or three grades above our $\mathrm{G}$ - they might rank as I or J. But, supposing we do not count them at all, saying that some freak of nature acting at that time may have produced them, what must we say about the rest? Pericles and Plato would rank, I suppose, the one among the greatest of philosophical statesmen, and the other as at least the equal of Lord Bacon. They would, therefore, stand somewhere among our unclassed $X$, one or two grades above $G-l$ et us call them between $H$ and $I$. All the remainder, the $F$ of the Athenian race-would rank above our $G$, and equal to or close upon our $H$. It follows from all this, that the average ability of the Athenian race is on the lowest possible estimate, very nearly two grades higher than our own-that is, about as much as our race is above that of the African Negro. This estimate, which may seem prodigious to some, is confirmed by the quick inteiligence and high culture of the Athenian commonalty, before whom literary works were recited, and works of art exhibited, of a far more severe character than could possibly be appreciate 1 by the average of our race, the calibre of whose intellect is easily gauged by a glance at the contents of a railway book-stall."

This argument is so ingenious and the conclusion so startling that I propose to assume for a few moments that the method is sound-that it is practicable to compare peoples so widely different in almost every respect as the English and Athenians upon a basis of the number and grade of their eminent men-and inquire whether it is fairly applied, whether it does, after all, show such a preeminence on the part of the Greeks as Galton asserts. The only changes I propose to make are such as in my opinion tend to insure fair play between the contending nations.

As we allow Athens to choose her ground, so to speak, and rest her claims upon the age of Pericles, we ought surely to allow the same privilege to England. The brightest period in her history, having in view the number 
of her great men and of the population from which they were drawn, was undoubtedly the age of Elizabeth.

The population of the country at that period is not accurately known, but it appears to have been not greater than four and a half millions. Against this we have in Athens only about 90,000 free citizens, or but two per cent of the number of Englishmen.

I have already given reasons, however, for holding that in questions of fame the illiterate and overburdened poor should be counted out. Now among the free citizens of Athens there was no such class as this; although the government was democratic, so far as concerned those who shared in it, the citizens were really an aristocratic caste, ruling over a vast population of slaves. There were, on the average, four or five of these latter to every man, woman and child of the Athenian population, and even the poorest families had at least one slave to do the lower sorts of manual labor. The education of boys appears to have been nearly universal, and it was not a mere smattering of the elements, enabling the pupil to write his name or spell out laboriously a few paragraphs, but lasted from the age of seven to that of sixteen, and was often followed by more advanced studies. The three main divisions were gymnastics, music and letters, and the course as a whole appears to have been a thorough initiation into the culture of the Athenian people. This culture was, as all will admit, one peculiarly favorable to the development of literary and artistic genius.

I have not been able to find even an estimate of the number of English people that could read and write in the time of Elizabeth; but it was some small percentage of the population. Of course the upper and middle classes were feeling in some measure the general intellectual awakening that followed the revival of learning and the invention of printing, but culture was by no means general in any class and scarcely touched the common people. Froude says in his "Life of Bunyan," "In those days there were no village 
schools in England; the education of the poor was an apprenticeship to agriculture or handicraft."

Without pretending to definite knowledge upon the matter I venture to suggest that it is at least a fair question whether more than two per cent of the people of England had such opportunities for culture that they can reasonably be classed, in this respect, with the free-born population of Athens.

Another circumstance in favor of the Athenians is, in my opinion, of almost equal importance. The development of literary and artistic genius is greatly stimulated by facility of access to great centres of culture, where one can come into contact with eminent men and their works, and gain an inspiration more personal and visible than can be gotten. from books. It is in capitals, and there only as a rule, that literature and art are organized, communication and sympathy established among men of promise, and an "atmosphere" created.

Upon this point I shall take the liberty of quoting Goetheagain. He has discussed the question at length, with his. usual sagacity and amplitude of information. Take for instance this concerning Béranger, whom he is contrasting with Schiller.*

"On the other hand, take up Berranger. He is the son of poor parents, the descendant of a poor tailor; at one time a poor printer's apprentice, then placed in some office with a small salary; he has never been to a classical school or university, and yet his songs are so full of mature cultivation, so full of wit and the most refined irony, and there is such artistic perfection and masterly handling of the language, that he is the admiration, not only of France, but of all civilized Europe.

"But imagine this same Beranger-instead of being born in Paris, and brought up in this metropolis of the world-the son of a poor tailor in Jena or Weimar, and let him commence his career, in an equally miserable manner, in such small places, and ask yourself what fruit would have been produced by this same tree, grown in such a soil and in such an atmosphere."

I suppose I need not insist on the fact that as a focus of

- Conversation with Eckermann, May 3, 1827. 
intellectual activity the London of Elizabeth bears no comparison to the Athens of Pericles. The Athenians were all, practically, inhabitants of one great town, and any man could meet with any other as often as he liked, while all came in daily contact with the great works of art that crowned the city. London, on the other hand, was hard to reach-how hard one may judge from the famous description of English roads in Macaulay's third chapter-and was not much of a place when you got there. It contained something like I50,000 people, of whom the great majority were ignorant artisans who must be classed, so far as culture is concerned, with the Athenian slaves.

Making due allowance for these things and assuming that the conditions other than race are about equal in the two cases, let us see if England can produce a list of men born within one century, which shall be other than ridiculous when set beside the one that Galton gives us from Athens. I choose the century beginning with I 550 .

Athenians.

Themistocles, Miltiades,

Aristides,

Cimon,

Pericles,

Thucydides,

Socrates,

Xenophon,

Plato,

Aeschylus,

Sophocles,

Euripides,

Aristophanes,

Phidias.
Englishmen.

Cromwell,

Sir Walter Raleigh,

Sir Philip Sidney,

Shakespeare,

Bacon,

Ben Jonson,

Spenser,

Milton,

Bunyan,

Dryden,

Locke,

Hobbes,

Jeremy Taylor,

Sir Isaac Newton.

Opinions will differ regarding these two lists; but few, I imagine, will go so far as to say that the Englishmen are outclassed.

It is not for me to praise Shakespeare, or Milton, or Cromwell, much less to depreciate Phidias or Sophocles. 
Some would say that to have produced Shakespeare was alone a sufficient title to greatness for any race, and enough to cast lasting doubt on all comparisons tending to make it appear less than others. Let the reader form his own opinion.

In such questions as these, where there is no definite criterion, we are necessarily more or less controlled by prejudice. In favor of the Englishmen there is the prejudice of race; in favor of the Greeks there is the prejudice of education. The writers of the latter people had a long start; they have been the school-books of Europe emerging from barbarism; they have grown with the growth of culture, and their fame is carried on by irresistible tradition. The fame of Shakespeare is still young, and it is only within the present century that he has come to be generally regarded as the peer of the great classic writers.

Anglo-Saxons of sensibility and culture regard Greek literature and art with an intensity of admiration which might be interpreted as a sense of their own inferiority. I would suggest, however, that this charm which the Greek spirit has for the northern races is the charm of difference rather than that of superiority. It is like the feeling of sex; just as there is something in what is womanly that appeals to men, and something in what is manly that appeals to women, so that which is Greek delights the modern nations without there being any question of greater or less in the matter at all. The Teutonic man, one may say, feels toward the spirit of his own race as toward a brother, but toward the Greek spirit as toward a mistress. This very capacity of admiring, and so assimilating, what is best in a different race is itself, perhaps, a title of greatness.

After all, were the Greeks an abler people than the AngloSaxon? Could they have advanced in liberty for a thousand years without falling into disorder? Could they have organized and maintained a commercial empire "greater than the Roman?" Could they have suppressed Napoleon and abolished the slave trade? 
Such questions are interesting, perhaps, but quite unanswerable. In the meantime I imagine that most persons who consider the facts dispassionately will agree with the that even if we accept Galton's method of comparison, there is small foundation for his judgment "that the average ability of the Athenian race is, on the lowest possible estimate, very nearly two grades higher than our own-that is, about as much as our race is above that of the African Negro."

But it can be shown, I think, that this method, no matter how carefully we allow for differences of social organization, is still hopelessly fallacious. It can be satisfactorily tested, it seems to me, by examining the historical grouping of the eminent men produced by any one people, with a view to finding out whether they appear with such approximate regularity as would be expected if greatness is a function of race. If one thing is to be the criterion of another it must be shown to bear some reasonably definite relation to it. In Galton's argument it is assumed that we have an equation of two variable quantities, of which one being determined, namely the number of great men, we can determine the other, that is race ability. Now it is demonstrable that there are other unknown quantities entering into this equation which are not determined, and whose presence vitiates the reasoning.

The conspicuous fact that one generation may be rich in famous men and another, a little earlier or later, quite barren of them, does not entirely escape Galton; but he endeavors to account for it, as he apparently must under his theory, by a change in the race itself. Let us see how he does this in the case of the Athenians. In a paragraph already quoted, the rise of this people is explained as follows:

"Athens opened her arms to immigrants, but not indiscriminately, for her social life was such that none but very able men could take any pleasure in it; on the other hand, she offered attrac- 
tions such as men of the highest ability and culture could find in no other city. Thus, by a system of partly unconscious selection, she built up a magnificent breed of human animals which . . . . produced the following illustrious persons."

Now for the causes of the decline of this breed.

"We know, and may guess something more, of the reason why this marvelously gifted race declined. Social morality grew exceedingly lax; marriage became unfashionable, and was avoided; many of the more ambitious and accomplished women were avowed courtesans, and consequently infertile, and the mothers of the incoming population were of a heterogeneous class. In a small sea-bordered country, where emigration and immigration are constantly going on, and where the manners are as dissolute as were those of Greece in the period of which I speak, the purity of a race would necessarily fail. It can be, therefore, no surprise to us, though it has been a severe misfortune to humanity, that the high Athenian breed decayed and disappeared."

Now is this entirely plausible, or even consistent? Both the rise and the decline of the race are ascribed to the same cause, namely immigration. Certainly, then, some reason should be given for supposing that there was a radical change in the character of the immigration: but no such reason is given. Until something more definite and convincing than this is brought forward we must believe that the natural characteristics of a race are comparatively stable, and that it takes a long time, as a rule, to transform them into something quite different. Believing this we cannot explain the instances of rapid rise and decadence, of which history is full, by saying that they are due to changes in the breed.

To examine this question a little more closely let us look for a few moments at the distribution of famous painters in the country that has been most noted for producing them; since artists are regarded by Galton as affording, along with literary men, the best illustration of the truth of his theory. For convenience, and in order to have something definite to refer to, I shall again make use of Nichol's Tables, already mentioned. Arranging the famous painters of Italy according 
to the dates of their birth-omitting two or three unimportant ones whose dates are uncertain-I have the following results:

Previous to the thirteenth century Italy produced no great painters. In the thirteenth century seven were born; in the fourteenth, seven; in the fifteenth, thirty-eight; in the sixteenth, twenty-three, of whom fourteen fall in the first half. In the seventeenth, eighteenth and nineteenth centuries a few scattered painters, none of them of very high merit.

The concentration in the fifteenth century, here apparent, becomes more striking when we examine that century by quarters. Six of the thirty-eight were born in the first quarter, eight in the second, eight in the third, and sixteen in the last. But the real pre-eminence of this period, the real intensity with which the light of fame beats upon this particular point, is very faintly suggested by figures. It will be better appreciated when I say that here, within a period of nine years, were born the three painters generally acknowledged to be the greatest that the world has produced: Titian (1475), Michelangelo (I477), and Raphael (1483)**

Now how can such facts as these be explained on the

* Famous Italian Painters Classified according to Their Time of Brrta. [Both the list and the notation indicating the relative excellence of the painters follow Nichol's rables. Other estimates would differ a good deal but would not alter the general result.]

Tzelfth Century.-None.

Thirteenth Century.-Guido da Siena, Margaritone d'Arezzo, Cimabue, Arnolfo del Cambio, S. Memmi, GIOTTO, Duccio.

Fourteenth Century.-T. Gaddi, ORCaGNa, Justus of Padua, Taddeo Bartoli, $\mathrm{S}$. Aretino, Lippo Dalmasio. Fra ANGelico.

Fifteenth Century.-First Quarter.-Masaccio, FilipPo LIPPI, Roselli, P. della Francesca, Gozzoli, Alberti.

Second Quarter.-Ghirlandaio, Pollaiuolo, G. Bellini, Mantegna, Benvenuto da Siena, PER UGINO, BotTICELli, Signorell.

Third Quarter.-Filipjino Lippi, Bonsignori, Crivelli, Francra, Pinturicchio, LEONARDO DA VINCI. L. di Credi, Luini.

Fourth Quarter.-Fra Bartolommeo, GIORGIONE, Marziale, RAPHAEL, L. Lotto, Palma Vecchio, Beccafumi, Sodoma, MICHELANGELO, S. Del Prombo, A. DEL SARTo, CORREGGIO, TITIAN, Dossi, Gatofalo, G. Romano.

Sixteenth Century.-First Half.-Parmigiano, Bordone, Bronzino, D. da Volterra, [347] 
theory that greatness is a comparatively constant function of race? Can it be supposed that by some occult action of the laws of selection the Italian people rapidly increased in natural ability of an artistic sort up to 1500 , and then as rapidly declined? If not, if such variations as these are observed in the same race, how can the number of eminent men produced be taken as a test of race ability?

The odds against this remarkable grouping being due to mere chance would be so great that no one, I suppose, would venture to attribute it to that, though I should be inclined to admit that the birth of the three transcendent artists within so very short a period as nine years was partly fortuitous.

Nor can it be said that genius, such as these painters. possessed, found some other path to fame in the periods preceding and succeeding the great time of art. On the contrary the time when there were famous artists in Italy was also the time, roughly speaking, when there were great men of letters and great statesmen, and in the age.succeeding all sorts of genius were obscured.

A study of Dutch and Flemish painters would lead to results essentially similar. Nearly all the great ones were born in the period $155^{\circ}-1650$.

To explain facts like these, and analogous ones that can be traced in the history of literature by any one who will take the trouble, we must suppose one of two things: first, that the natural ability of races undergoes rapid changes in degree and kind, owing to the action of forces as yet unknown; or, second, that the appearance of famous men is dependent upon conditions other than race.

The second conclusion is so much simpler and agrees so. much better with known facts, that I imagine few will

Salviati, Vasari, G. Mantuano, TINTORETTO, T. Zucchero, Bassano, A. Schiavone, P. Veronese, Baroccio, Manzuoli.

Second Half.--The three Caracci, Carduccio, Caravaggio, G. RENI, Allori, Domenichino, Gorrcino.

Sevententh Century.-SALvator Rosa, born in 16I5, is the last Italian painter of great reputation. 
embrace the first. And if we accept the second we must also, I think, conclude that able races produce at all times a considerable number and variety of men of genius of whom only a few encounter those favorable conditions that enable them to achieve fame.

To make perfectly clear the grounds of this last inference let me suggest a comparison. Suppose one were following a river through a valley, and from time to time measuring its breadth, depth and current with a view to finding out how much water passed through its channel. Suppose he found that while in some places the river flowed with a swift and ample current, in others it dwindled to a mere brook and even disappeared altogether, only to break out in full volume lower down. Would he not be led to conclude that where little or no water appeared upon the surface the bulk of it must find its way through underground channels, or percolate invisibly through the sand? Would not this supposition amount almost to a certainty if it could be shown that the nature of the rock was such as to make the existence of underground channels extremely probable, and if in some cases they were positively known to exist? I do not see that the inference is any less inevitable in the case before us. We know that a race has once produced a large amount of natural genius in a short time, just as we know that the river has a large volume in some places. We see, also, that the number of eminent men seems to dwindle and disappear; but we have good reason to think that social conditions can cause genius to remain hidden, just as we have good reason to think that a river may find its way through an underground channel. Must we not conclude, in the one case as in the other, that what is not seen does not cease to be, that genius is present though fame is not?

There are reasons for believing that even where our river seems fullest a great part of its flow is underground. In the age of Elizabeth, for instance, there was a complete lack of those masters of painting and sculpture who made [349] 
the chief glory of the age of Lorenzo de Medici. Yet later history has shown that the English people are by no means lacking in this sort of genius. The inference is that it was present but undeveloped.

The fact that genius can develop into greatness at some times and cannot at others is by no means inscrutable. The reasons for it can be indicated in a general way, though they are so complex that it is difficult to point out their precise application to various periods of history.

In the case of painting, for instance, it is easy to show that a number of conditions other than natural ability must concur before excellence can exist. Among those generally recognized as essential to great art of any kind are the three following:

First, a perfect technique, achieved by the accumulated experience of many generations, and kept alive and promulgated by a succession of masters. This technique cannot be learned from books or by looking at finished pictures. "Studio traditions are to be acquired only in the studio." * It calls for personal contact and a long training that begins in childhood. In order that this training may be had it seems important that art should rest upon art-handicrafts, which maintain a large number of skilled craftsmen, of whom the most gifted become great artists. In the fifteenth century painting was a great art largely because it was a recognized and flourishing trade, and because the kindred trade of goldsmithing also flourished. The great painters and sculptors were first of all craftsmen. They were apprenticed when eight or ten years old, and for a long time were contented to watch their master and copy his methods as closely as possible. So general was this and so close the imitation that it is frequently impossible to distinguish the work of a master from that of his pupils.

*w. J. Stillman.

Lombroso, "The Man of Genius," English Translation, p. I53, notes that " the establishment of a school of painting, even when it is the result of an importation, makes an artistic centre of a place which was not so previously." 
The greatest painters grew up in these traditions, and spent their youth in imitation. Raphael was a pupil of Perugino, Perugino of Verocchio, he of Donatello, and so on. Mr. Stillman says* that Raphael "had an extraordinary and, so far as we can judge by the history of painting, unique power of absorbing the ideas and feelings of other men. He caught the color of every great artist he approached."

A second indispensable condition is an "art-atmosphere," a general and unaffected interest in the creation of beauty, and the appreciation of the good to which that interest naturally leads. This art-atmosphere is itself a social product, and usually grows with the growth of art, in part its cause and in part its effect. Little can be done in any line of work without appreciation, sympathy, friendly criticism; and artists and poets, being extremely sensitive, can least of all do without these. They all agree, I believe, that no headway can be made without an "atmosphere," and, where people in general are cold, artists flock together and try to keep one another as warm as possible.

Thirdly, I believe that no very great art has been produced except where there was an aspiring and successful general life, furnishing symbols that spoke to a common enthusiasm. Stimulated by this enthusiasm art raises these symbols to the highest types of beauty. The general life and the symbols which stand for it, may be religious, as with most of the earlier mediæval painters, or they may be political, or a union of the political with the religious, as was, I believe, the case with much of the greatest art of Athens and Venice. The art which separates itself from great ideas and general feelings, which aims solely at sensuous effects, is usually felt to fall short of art's highest functions.

I do not say that these are all the essential conditions of great art, but they seem to be essential, and that they are so helps one to understand the fact, already shown, that the

" "Old Italian Masters," p. 228. 
development of artistic genius is dependent upon historical tendencies and the spirit of the time. A complete philosophy of art, showing just what the favoring conditions are and how they arise, has yet to be written.

How present conditions in the United States bear upon the development of artistic genius may be gathered from the statement of an American painter of acknowledged eminence, Mr. F. D. Millet.*

"The brief chapters in the career of an American artist may be summarized as follows: He spends the most impressionable years of his life between studying in an art school and some occupation. which gives him fair promise of sufficient recompense to enable him to pursue bis studies abroad. He enters an art school in a foreign capital, and proves that with all the disadvantages of his early education he can take rank with any student in any branch of the profession. After his student days are over he has to decide the question whether to expatriate himself and lead a congenial life in the stimulating atmosphere of professional sympathy and support, or to return home and add his efforts to the sum of individual endeavors directed with rare devotion and self-sacrifice toward the development of artistic talent in his native country. If he chooses the former course, he may and often does become known to fame and fortune; if he selects the latter and nobler career, his life becomes a round of teaching, struggles with sordid conditions of professional life, and the wearing and soul-killing battle with lack of appreciation and encouragement, not to say distrust."

"If in the whirl of commercial prosperity, and all the distractions of active and ultra-modern life and the accompanying unrest which is death to artistic production, we find a constantly increasing number of serious artists, what may we not expect when the luxury of leisure is possible in this country!"

There is, then, reason to believe that it is not native incapacity that retards the rise of art in this country, but sheer ignorance and lack of interest resulting from generations of one-sided development.

Since Galton includes distinguished oarsmen among his men of genius, I may be allowed at this point, to draw a comparison from the game of base-ball. It is as difficult for

" "The United States of America," edited by N. S. Shaler, Vol. ii, pp. 415, 420. 
an American brought up in the western part of our country to become a good painter as it is for a Parisian to become a good base-ball player, and for similar reasons. Base-ball is a social institution with us; every vacant lot is a school, every boy an aspirant for success. The technique of the game is acquired in childhood, and every appearance of talent meets with enthusiastic appreciation. Hence we have many good players and a few great ones. Now it is probable that Frenchmen are from time to time born with a genius for this game, but how can it be developed? What chance do they have to achieve excellence or acquire fame? They probably remain in lifelong ignorance of their own possibilities. If the ambition did arise in one of them it would probably come too late for him to make up the lack of early training.

This somewhat humble illustration is believed to be well worthy of consideration by those who imagine that a social career can be independent of circumstances and the spirit of the time.

The principles that apply to painting hold good, mutatis mutandis, in other social careers. The dependence upon conditions other than race, the concentration of certain kinds of greatness at certain epochs, exist in all the arts and in literature. The concentration of English dramatists toward the end of the sixteenth century is as conspicuous as that of the Italian painters a century earlier. Shakespeare, Beaumont, Fletcher, Ford, Webster, Massinger and Jonson were born within a period of twenty-three years, while in the centuries since then England has produced only one or two dramatists comparable with the least of these. A similar grouping may be observed in the earlier group of American men of letters. Professor McMaster, in his history, speaks of it as follows: *

"The men whose writings now form our national literature, the men we are accustomed to revere as intellectual patriarchs, all whose

* vol. i, p. 76. 
works have become classics, belong, without exception, to the generation which followed the Revolution. Irving was not a year old when peace was declared. Cooper was born in the same year Washington went into office. Halleck, one year later. Prescott, in the year Washington came out of office. The constitution was five years old when Bryant was born. The first year of the present century witnessed the birth of Bancroft, and, before another decade had come and gone, Emerson was born, and Willis, and Longfellow, and Whittier, and Holmes, and Hawthorne, and Poe. . . . Scarcely a twelvemonth went by unmarked by the birth of a man long since renowned in the domain of letters-1783, 1789, 1790, 1791, I794, $1795,1796,1800,1803,1806,1807,1808,1809,1811,1814$, such is the almost unbroken succession."

I find, however, that grouping is not so conspicuous in literature as it is in art; and in science it is not at all obvious. Since the Reformation there has been a tolerably regular and constant advance of verifiable knowledge, in which all civilized nations have participated. Though it is no doubt true, as Galton points out, that the fame of a man of science is likely to rest upon some striking discovery which might easily have been made by some one else-since the time had arrived when it could not long be postponedyet I am not sure but scientific genius is, after all, more independent in its development than any other. If so it is because science, as a social institution, is farther-reaching, and more accessible to those fitted to share in it, than is any other institution. Since the invention of printing and the consequent diffusion of books, the scientific men of all nations have formed a single co-operating group, enabled to co-operate by the facility of communication and by the exact and verifiable character of their work. To the man with a natural turn for it, science, and the inspiration to pursue science, are communicable through books and correspondence. There is no "local color" in science; the "atmosphere" is as essential as it is in art, but it is purely intellectual, and depends relatively little upon personal contact. Compared with the artist the man of science is cold, and can carry on his pursuits with but little emotional 
support from his immediate surroundings. Letters, journals, and the notice of his work by others in the same line of research suffice for him.

Literature has some of these characteristics, but not others. It has a great advantage over painting and sculpture in that it is capable of cheap diffusion through printing. It is for this reason, apparently, that literature arises earlier in a new country than do the other arts. Painting and sculpture cannot well be learned except through intercourse with a master, nor is it possible adequately to reproduce great works and disseminate them over the earth. Accordingly it may happen, as is the case over the greater part of the United States, that no conception of these arts exists except a vague and false one derived from reading and from familiarity with cheap mechanical reproductions. The arts of illustrating and engraving, however, precisely because their products are easily disseminated, are in a comparatively flourishing state and are doing much to arouse an art-sense among us. As compared with scientists, men of letters have probably more need of the emotional stimulus and support that come by personal contact. The passionate desire of young men of letters to see and know the heroes of their craft is depicted in many autobiographies. I suppose that when Mr. Howells went to Boston and saw Lowell and Dr. Holmes for the first time it meant more to him than a like experience would have meant to a young chemist or mathematician.

In the matter of propagation in a new country sculpture and painting may be compared to heavy-seeded trees, like oaks and walnuts, which, because of the difficulty with which they are sown, make their way slowly into a region where the species is not already established. Literature and science, for the reasons just given, are comparatively lightseeded, furnished like thistledown with facilities for transportation, and so spread very rapidly where the conditions are favorable for their growth.

These, however, are details which have little to do with 
the general question under consideration. The main fact is that great success in any career calls for two things: natural ability, and a social mechanism to make this effective. Genius can reach high, as a rule, only 'when it stands on top of a culminating institution. When one looks off at the horizon of a rolling landscape he will notice two or three trees that seem to overtop all others. They seem to do so partly because they are really tall trees, and partly because they stand near the summit of the highest visible ridge. There may be higher trees in the valley-probably there are many equally high-but these do not appear. It is quite the same with men. The age of Elizabeth and the age of Lorenzo de Medici were, so to speak, natural elevations in the histories of England and Italy, resting upon which it was easy for genius to attain fame. I do not mean that they were superior, on the whole, to our own time, but they were more favorable to the development of certain sorts of ability. Individual faculty is real and powerful, and there is no greatness without it, but no man is tall enough to stand upright and fixed in the stream of history. He can at most swim a few strokes against or across it. "Who can separate his ship from the waves on which it is floating?"

I trust I have made clear my reasons for thinking that estimates of the worth of races based upon the number and grade of the eminent men they produce, have no scientific justification unless it be possible to eliminate those social conditions that have quite as much to do with the matter as race. That such elimination is usually impossible, I suppose all will admit. To show, in a general way, the power of historical forces is easy, but to take exact account of them, to predict their future operation, to show just how they differ in different times and countries, and how much must be allowed for that difference, is, in the present state of historical science, quite out of the question. If, however, cases can be found where two races mingle and compete in the same social order, and under conditions substantially 
the same, a valuable comparison might perhaps be made. Are there any such cases?

The negroes and the whites in the United States could not be so compared, as Galton justly remarks. Neither, for similar reasons, would it be possible to compare the older English stock of the same country with recent immigrants of other races. Perhaps no cases can be found in which the use of the method is more defensible than in the comparison of the ordinary English with the Scotch and the NorthCountry men, suggested by Galton, and the comparison between the Jews and other races carried out by Mr. Jacobs in the paper published by the Anthropological Institute. *

The question here is whether the peoples mentioned are really on an equality in respects other than race. It is commonly reported that the standard of education and individual freedom among the Lowland Scotch is considerably higher than it is in England. Galton says as much, and contrasts the well-being of the northern peasantry with "the draggled, drudged, mean look of the mass of individuals, especially of the women, that one meets in the streets of London and other purely English towns." Now to assume that this degradation is due to inferiority of race seems to me to be a begging of the whole question. Before doing that it shculd be shown that nurture and social conditions cannot thus degrade the members of a good race. I do not think it is possible to show this, and I would cite the comparison of East and West End Jews, already referred to, as indicating the contrary. $\dagger$

If the comparison between English and Scotch were made at the time of Elizabeth it would seem to show that the English were a far superior race at that period, since Scotland was then conspicuously lacking in distinguished men.

* Journal, Vol, xv, p. 35I.

$\dagger$ I could cite abundant evidence on this point, but do not suppose that it is necessary.

† Lombroso, "The Man of Genius," English Translation, p. 154, makes a similar remark, ascribing the former deficiency of scotch genius to religious intolerance. 
If this lack was due to the backwardness of social development, how can we assume that the present apparent superiority of Scotland is not likewise due to social conditions, instead of to race? The men of the north may be "a fraction of a grade superior," but, if so, the fact needs further proof.

The author of the paper upon the ability of the Jews ascribes a great deal to their social conditions, which still differ much from those of the races with whom they mingle. Thus he explains their musical pre-eminence partly by "the home character of their religion, which necessarily makes music a part of every Jewish home." Again, "Persecution, when not too severe, has probably aided in bringing out their best powers; to a high-spirited race, persecution, when there is hope of overcoming it, is a spur to action."

Such comparisons, when made with as much thoroughness and caution as this one, are certainly interesting and valuable; and if they do not arrive at precise results they are no worse off in this respect than most social investigations.

On the whole it seems to me that the relation between genius and fame is fairly well represented by the comparison, suggested at the outset, of a farmer sowing mixed seeds in a furrow which traverses a great variety of ground. Here many come up and flourish, there none, and there again only those of a certain sort. The seed-bag is the race, the soil historical conditions other than race, the seeds genius, and the crop fame.

It is true that knowing so little as we do of the forces governing heredity and degeneration, we cannot be sure that the seeds are sown with anything like uniformity, that the amount of natural ability produced from a given stock is approximately constant. But this is certainly the simplest supposition, and it would seem reasonable to accept it until the contrary is shown.

Charless H. Cooley.

University of Michigan. 